Journal of Energy and
Environmental Sulial publication of the International Society for Energy, Environment and Sustainability (ISEES)
Journal homepage : www.jees.in

\title{
A comparative study of thermal decomposition kinetics of cellulose, hemicellulose, and lignin
}

\author{
Vaibhav Dhyani ${ }^{\mathrm{a}}$, Jitendra Kumar ${ }^{\mathrm{a}}$, Thallada Bhaskar ${ }^{\mathrm{a}, \mathrm{b},{ }^{*}}$ \\ aBiomass Conversion Area (BCA), Material Resource Efficiency Division (MRED), CSIR-Indian Institute of Petroleum (IIP), Dehradun 248005, India \\ ${ }^{b}$ Academy of Scientific and Innovative Research (AcSIR), India
}

\section{A R T I C L E I N F O}

Received : 20 June 2019

Revised : 07 September 2019

Accepted : 04 October 2019

Keywords:

Pyrolysis, Kinetics, Cellulose,

Hemicellulose, Xylan, Lignin

\begin{abstract}
A B S T R A C T
In this work, decomposition behaviors of cellulose, xylan (representative hemicellulose subtype), and lignin have been compared using thermogravimetric analysis (TGA) and differential thermogravimetry (DTG). The TGA data were also used to perform kinetic analysis using non-isothermal isoconversional methodology (Friedman's method). The values of average activation energy of decomposition of cellulose, xylan, and lignin were calculated as $137.80 \mathrm{~kJ} / \mathrm{mol}, 202.74 \mathrm{~kJ} / \mathrm{mol}$, and $151.55 \mathrm{~kJ} / \mathrm{mol}$ respectively. The pre-exponential factor was calculated via Kissinger's equation. The thermodynamic significance of kinetic analysis has also been extended here. This study can help in understanding the heterogeneity in the pyrolysis behavior of the whole biomass by elucidating the decomposition properties of the individual components.
\end{abstract}

\section{Introduction}

Biomass is being extensively studied worldwide for bio-fuel generation via pyrolysis. Study of decomposition behavior and the associated kinetics is essential for process optimization and scale-up. However, biomass decomposition is challenging to generalize because of its heterogeneous nature. Different biomass types comprise varying ratios of three key components: cellulose, hemicellulose, and lignin. Cellulose is a linear chain polysaccharide of repeating D-glucose (a six-carbon ring, also known as pyranose) units linked to each other by acetyl bonds (-O-, $\beta$ $(1 \rightarrow 4)$ glycoside linkage). Hemicelluloses are heteropolysaccharides of different monomers such as glucose, galactose, mannose, xylose, arabinose, and glucuronic acid. These monomers are present in the form of polysaccharides such as xylan, glucuronoxylan, arabinoxylan, glucomannan, and xyloglucan (Dhyani and Bhaskar, 2019, 2018a). Lignin is a high molecular weight polymer, which may constitute as much as 20 $35 \%$ of the organic matrix of wood and other vascular plants (Wang et al., 2017). It is a three-dimensional highly branched polymer, made up of phenylpropane units attached by alkyl-aryl ether bonds. Hemicelluloses and lignin cover the cellulose microfibrils (Hergert, 1971; Kawamoto, 2017; Patwardhan et al., 2011).

The heterogeneity in the biomass properties arises because of different decomposition temperature regimes and varying decomposition rates of each component (Dhyani et al., 2017; Yang et al., 2007). Although much work has already been done in understanding the chemical nature of the biomass components, relatively less work has been performed on decomposition kinetics of the individual biomass components (Miller and Bellan, 1997; Yeo et al., 2017).

In this work, the decomposition of biomass components was studied using thermogravimetric analysis (TGA). The activation energy $\left(E_{\alpha}\right)$ of decomposition of biomass components was estimated using Friedman's differential isoconversional method, following the recommendations by International Confederation for Thermal Analysis and Calorimetry (ICTAC) (Vyazovkin et al., 2014, 2011). The values of the preexponential factor were calculated using Kissinger's equation, and the reaction models were predicted using the combined kinetic method. The values of activation energy were also used for calculating the thermodynamic parameters, enthalpy entropy, and Gibbs free energy (Awasthi et al., 2019).

This study can help in shedding light on the complex behavior of biomass pyrolysis and understanding the convolution of the contribution of the individual components on the whole biomass.

\section{Materials and methods}

\subsection{Feedstock}

Cellulose, xylan from beechwood (representative polysaccharide for hemicellulose), and kraft lignin were obtained from Sigma-Aldrich. The proximate analysis of the individual biomass components on a moisturefree basis is given in Table 1.

\footnotetext{
*Corresponding Author: : tbhaskar@iip.res.in
} 
Table 1. Proximate analysis of biomass constituent

\begin{tabular}{l|c|c|c}
\hline Component & $\begin{array}{c}\text { Volatile matter, } \\
\text { wt.\% }\end{array}$ & $\begin{array}{c}\text { Fixed carbon, } \\
\text { wt.\% }\end{array}$ & $\begin{array}{c}\text { Ash, } \\
\text { wt.\% }\end{array}$ \\
\hline Cellulose & 95.0 & 5.0 & 0.01 \\
Xylan & 72.0 & 16.7 & 11.3 \\
Lignin & 95.5 & 3.0 & 1.5 \\
\hline
\end{tabular}

\subsection{Thermogravimetric analysis}

The thermogravimetric analysis (TGA) was performed in a DTG-60 unit (Shimadzu, Japan). The weight-loss profiles obtained from TGA runs were used for proximate and kinetic analysis. Moisture, ash, and volatile matter were obtained via the ASTM standards, E871 (drying for $30 \mathrm{~min}$ at $103 \pm 1^{\circ} \mathrm{C}$ in), E1755 (oxidation at $575 \pm 25^{\circ} \mathrm{C}$ ), and $\mathrm{E} 872$ (rapid de-volatilization at $950^{\circ} \mathrm{C}$ ). The fixed carbon content was calculated by difference:

$\%$ Fixed Carbon $=100-(\%$ Moisture $+\%$ Volatile Matter $+\%$ Ash $)$

\subsection{Kinetic analysis}

The rate of progression in terms of 'conversion' with Arrhenius expansion can be stated as:

$$
\left(\frac{d \alpha}{d t}\right)_{\alpha}=A_{\alpha} e^{-\frac{E_{\alpha}}{R T}} f(\alpha)
$$

Kinetic analysis refers to the determination of parameters, preexponential factor $(A)$, activation energy $(E)$ and the reaction model $(f(\alpha))$ which are knows to vary throughout the reaction (or conversion) for the case of biomass pyrolysis (Dhyani and Bhaskar, 2018b). To perform the kinetic analysis, the non-isothermal TGA data were converted into conversion $(\alpha)$ using the following equation (Fekhar et al., 2018):

$$
\alpha=\frac{m_{\text {initial }}-m_{t}}{m_{\text {initial }}-m_{\text {final }}}
$$

where, $m_{\text {initial }} m_{\text {final }}$ and $m_{t}$ are initial weight, final weight, and weight at any time ' $t$ ' during the thermal decomposition.

$\left(\frac{d \alpha}{d t}\right)_{\alpha}$ in equation (2) is the instantaneous time derivative of $\alpha$ obtained from equation (3).

The kinetic analysis of individual biomass components, cellulose, xylan, and lignin was performed using the non-isothermal isoconversional method. These methods can be considered superior to conventional modelfitting methods as they yield the value of activation energy without assuming any reaction model in advance (Dhyani and Bhaskar, 2018b).

Friedman's method, which is a differential isoconversional method, was used for the calculation of activation energy (Friedman, 1964). The working equation for Friedman's method can be given as,

$$
\ln \left(\frac{d \alpha}{d t}\right)_{\alpha, i}=\ln \left[f(\alpha) A_{\alpha}\right]-\frac{E_{\alpha}}{R T_{\alpha, i}}
$$

In the above equation, $i$ denotes different temperature programs at which the non-isothermal TGA runs are being conducted, $\ln (d \alpha / d t)_{\alpha, i}$ denotes the set of $d \alpha / d t$ values at a fixed value of conversion at different heating rates and similarly, $T_{\alpha, i}$ is the temperature at which ' $\alpha$ ' conversion has taken place at different heating rates. For a fixed value of conversion, the term $\ln \left[f(\alpha) A_{\alpha}\right]$ is constant. Thus, for each value of $\alpha$ the plot of $\ln (d \alpha / d t)_{\alpha, i}$ vs. $\left(1 / T_{\alpha, j}\right)$ should give a straight line with slope equal to $\left(-E_{\alpha} / R\right)$.

The non-isothermal TGA data from six different heating rates $(5,10$, $15,20,30$, and $40^{\circ} \mathrm{C} / \mathrm{min}$ ) was used for the calculation of slope in equation (4)

$A_{\alpha}$ was calculated using Kissinger's equation (Kissinger, 1956),

$$
A_{\alpha}=\frac{\beta E_{\alpha} \exp \left(\frac{E_{\alpha}}{R T_{m}}\right)}{R T_{m}^{2}}
$$

where $\beta$ is the heating rate and $T_{m}$ is the temperature at the maximum conversion rate.

Reaction models describe the quantitative relationship between conversion rate and extent of conversion. They are a mathematical translation of the reaction progression mechanism.
Several reaction models for the solid-state have been developed and tested. These models have either been developed based on the assumption of the reaction mechanismor by empirical fitting with little physical meaning. A survey of different reaction models for solid-state kinetics is provided in Dhyani and Bhaskar (2018).

Šesták and Berggren (1971), gave the following mathematical expression for the representation of all reaction models in a single equation.

$$
f(\alpha)=\alpha^{m}(1-\alpha)^{n}(-\ln (1-\alpha))^{p}
$$

Equation (6), can generate any reaction model for different values of constants, $m, n$ and $p$.

A simplified form of the above equation can be given as,

$$
f(\alpha)=c(\alpha)^{m}(1-\alpha)^{n}
$$

where $c, n$, and $m$ are unknown constant parameters which can be adjusted to fit every decomposition scheme.

\subsection{Thermodynamic analysis}

Thermodynamic parameters, enthalpy $(\Delta H)$, Gibbs free energy $(\Delta G)$, and entropy $(\Delta S)$ were calculated using equations (8) to (10).

$$
\begin{aligned}
& \Delta H=E-R T_{\alpha} \\
& \Delta G=E+R \cdot T_{m} \cdot \ln \left(K_{B} \cdot \frac{T_{m}}{h \cdot A}\right) \\
& \Delta S=\frac{\Delta H-\Delta G}{T_{m}}
\end{aligned}
$$

In equation (9) $h$ is the Planck constant $\left(6.62607004 \times 10^{-34} \mathrm{~m}^{2} \mathrm{~kg} \mathrm{~s}^{1}\right)$ and $K_{B}$ is the Boltzmann constant $\left(1.38064852 \times 10^{-23} \mathrm{~m}^{2} \mathrm{~kg} \mathrm{~s}^{-2} \mathrm{~K}^{-1}\right)$.

\section{Results and discussion}

\subsection{Thermogravimetric analysis}

The thermal decomposition profiles of cellulose, xylan, and lignin at heating rates of $5,10,15,20,30$, and $40^{\circ} \mathrm{C} / \mathrm{min}$ are shown in Figure 1. A lateral shift inthe TGA and DTG profiles can be observed with increasing heating rates, which can be attributed to the discrepancy in heat flow rate inside the biomass particles with variation in the heating program. It can be observed that the decomposition of cellulose is mainly confined in the temperature range of 300 to $350^{\circ} \mathrm{C}$ (Figure 1 (a) \& (b)), xylan decomposed predominantly between 250 to $300^{\circ} \mathrm{C}$ (Figure 1 (c) \& (d)), and lignin demonstrated a broad range of decomposition extending from 200 to $700^{\circ} \mathrm{C}$ (Figure 1(e) \& (f)). Although for each heating program, the percent residual solid showed some variation, the mean residual solid at $700^{\circ} \mathrm{C}$ for cellulose, xylan, and lignin were $11 \%, 29 \%$, and $35 \%$ respectively.

The values of conversion obtained from the heating program of $10^{\circ} \mathrm{C} /$ min normalized between 0 to $1\left(\alpha_{T=200^{\circ} \mathrm{C}}=0\right.$ and $\left.\alpha_{T=700^{\circ} \mathrm{C}}=1\right)$ are shown in Figure 2(a). It can be observed that cellulose decomposition reached the conversion value of 0.9 at $375^{\circ} \mathrm{C}$, while xylan and lignin reached the same conversion values at $465^{\circ} \mathrm{C}$ and $530^{\circ} \mathrm{C}$ respectively. The peak value of the rate of conversion for cellulose was significantly higher than the xylan and lignin (Figure 2(b)). If the interaction between the biomass components is ignored the DTG profile of any whole biomass can be constructed by knowing the composition of biomass components. To illustrate this, a DTG profile of pseudo biomass comprising of an equal percentage of cellulose, xylan, and lignin is also shown in Figure 2(b).

\subsection{Results of the kinetic analysis}

The comparison of activation energy $\left(E_{\alpha}\right)$ calculated using Friedman's equation for the three componentswas made between the conversion $(\alpha)$ values of 0.2 to 0.8 (Figure 3(a)). It was observed that cellulose demonstrated a decreasing $E_{\alpha} \nu$ s. $\alpha$ dependency $\left(\left(E_{\alpha}\right)_{\text {average }}=137.80 \mathrm{~kJ} /\right.$ mol), indicating an irreversible-endothermic decomposition. Decomposition of xylan $\left(\left(E_{\alpha}\right)_{\text {average }}=202.74 \mathrm{~kJ} / \mathrm{mol}\right)$ showed a trend close to cellulose decomposition till $\alpha=0.65$, followed by a sudden increase in $E_{\alpha}$. An increasing $E_{\alpha}$ vs. $\alpha$ dependency $\left(\left(E_{\alpha}\right)_{\text {average }}=151.55 \mathrm{~kJ} /\right.$ mol) throughout the decomposition range was observed for lignin, which is an indication of parallel and competing reactions.

The values of ${ }_{\mathrm{In}}\left(A_{\alpha}\right)$ obtained from Kissinger's equation follow a tread similar to $E_{\alpha}$. The ${ }_{\text {In }}\left(A_{\alpha}\right)$ vs. $\alpha$ plot obtained at the heating rate of $10^{\circ} \mathrm{C} /$ 

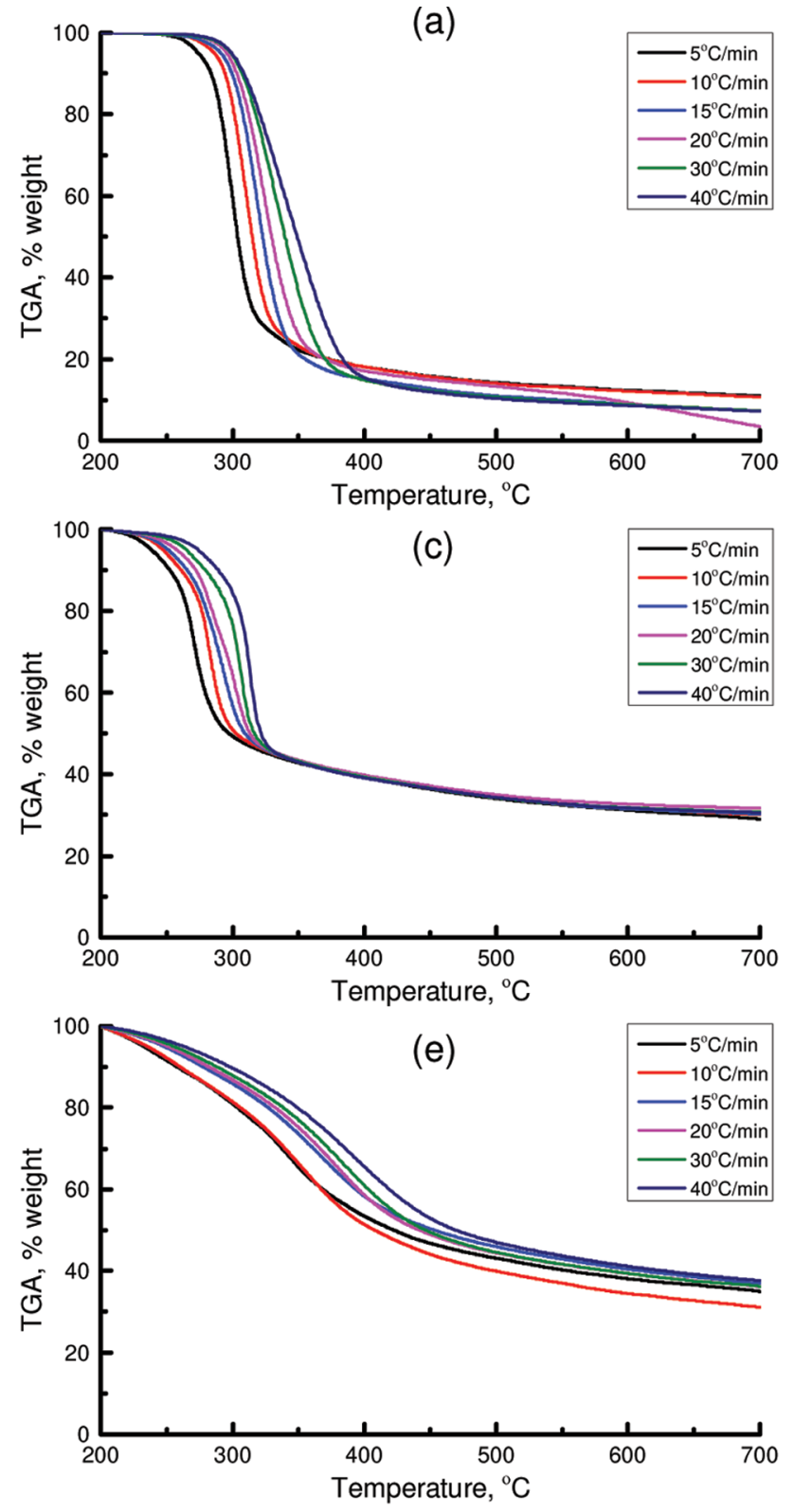

(b)

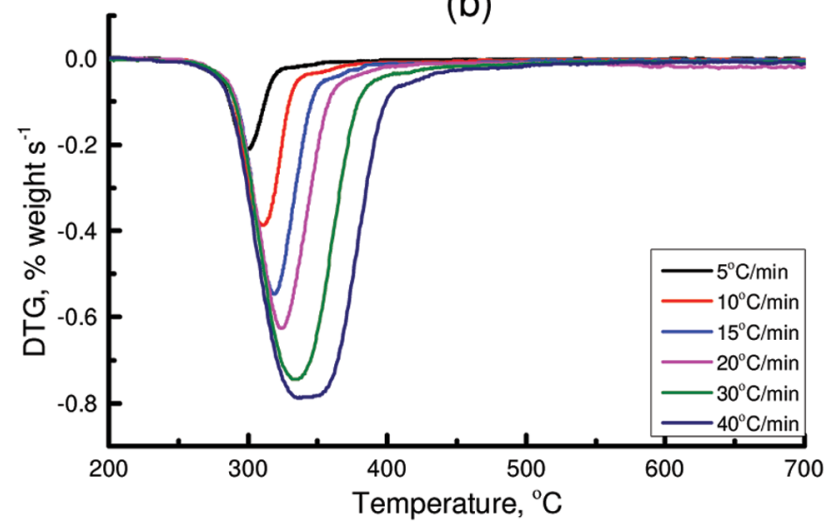

(d)

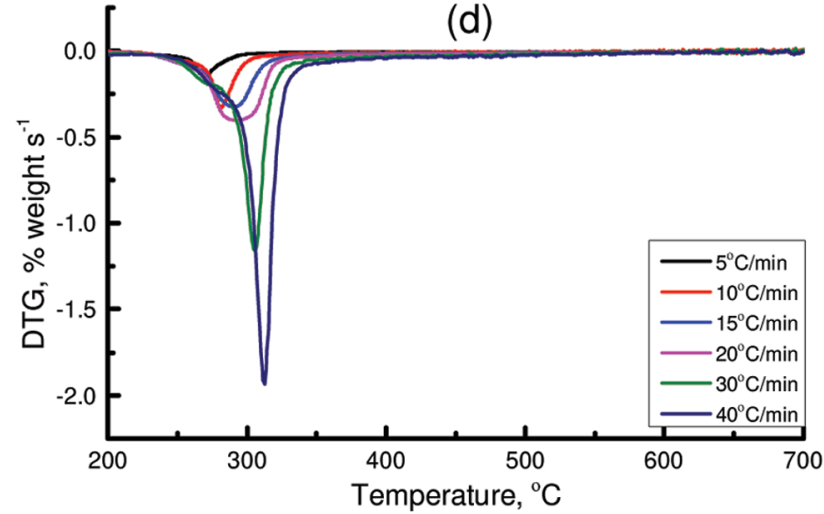

(f)

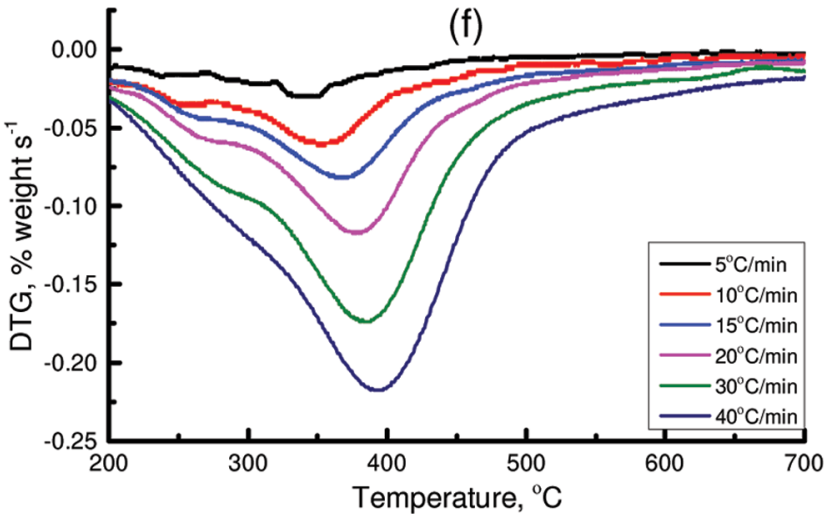

Figure 1.

TGA ((a), (c) and (e)) and DTG ((b), (d) and (f)) profiles for cellulose, xylan, and lignin respectively

min is shown in Figure 3(b). It can be observed that ${ }_{\text {In }}\left(A_{\alpha}\right)$ values increase rapidly as the conversion increases. This can be attributed to an increase in the collisions in the reaction system at higher conversion values, which is dependent on temperature in the present study. Although ${ }_{\text {In }}\left(A_{\alpha}\right)$ is an indirect measure of reactivity of the system, a quantification of the reactivity can only be made by evaluation of changes in the entropy of the system against conversion.
The $f(\alpha)$ vs. $\alpha$ profile obtained by substituting the values of $E_{\alpha}$ and $A_{\alpha}$ in TGA data is shown in Figure 3(c), while the results of non-linear curve fitting (equation 7) on the experimental data are shown in Figure 4. The values of the parameters $c, n$, and $m$ for cellulose, xylan, and lignin are mentioned in Table 2.

Table 2. Results of fitting of experimental data to $f(\alpha)=c(\alpha)^{m}(1-\alpha)^{n}$

\begin{tabular}{|c|c|c|c|c|c|c|c|}
\hline \multirow[t]{2}{*}{ Component } & \multicolumn{2}{|c|}{$c$} & \multicolumn{2}{|c|}{$n$} & \multicolumn{2}{|c|}{$m$} & \multirow[t]{2}{*}{ Adj. R-Square } \\
\hline & Value & Std. error & Value & Std. error & Value & Std. error & \\
\hline Cellulose & 48.370 & 13.679 & 9.234 & 0.156 & 17.364 & 0.284 & 0.999 \\
\hline Xylan & $9.021 \times 10^{7}$ & $1.296 \times 10^{8}$ & 10.590 & 0.835 & 17.601 & 1.361 & 0.994 \\
\hline Lignin & $9.513 \times 10^{-6}$ & $3.201 \times 10^{-5}$ & -6.181 & 1.666 & -2.899 & 3.588 & 0.990 \\
\hline
\end{tabular}




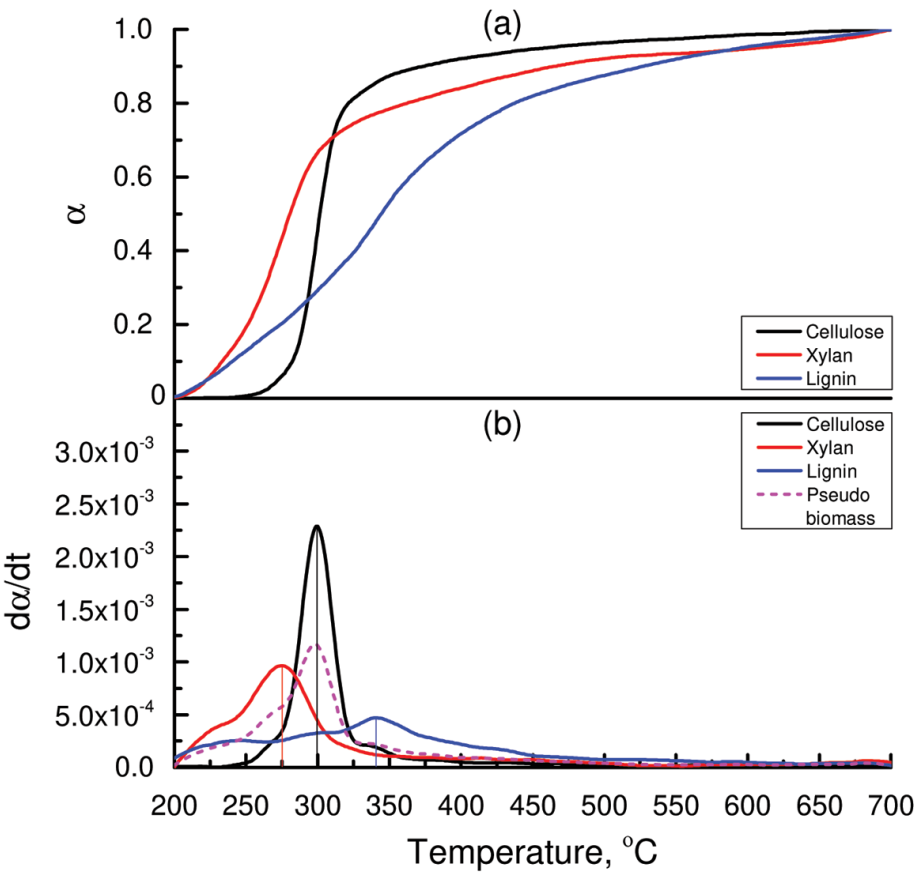

\subsection{Results of thermodynamic analysis}

A comparison of $\Delta H, \Delta G$, and $\Delta S$ vs. $\alpha$ for each biomass component at the heating rate of $10^{\circ} \mathrm{C} / \mathrm{min}$ has been shown in Figure 5. The $\Delta H \nu s_{\alpha}$. (Figure 5(a)) profiles for all the biomass components is highest near $\alpha=$ 0.8 , indicating that the decomposition process is more endothermic near the completion of the reaction. The $\Delta G_{\alpha}$ vs. $\alpha$ (Figure 5(b)) curves don't show any considerable variation with conversion, which indicates that the available energy of the reactants stays almost constant during the pyrolysis reaction (Kaur et al., 2018). $\Delta G_{\alpha}$ values are highest for lignin, followed by cellulose and xylan. The variations in entropy of the system comply with the changes in enthalpy confirming that the reaction systems are most reactive near the completion (Figure 5(c))

\section{Conclusions}

Biomass is composed of three principal components, cellulose, hemicellulose, and lignin. The overall decomposition properties of the biomass are results of convolution of decomposition profiles of individual components. In this work, the decomposition behavior of cellulose, xylan, and lignin was studied using TGA/DTG. The TGA results were also used for calculation of kinetic parameters and thermodynamic properties. Most of the cellulose decomposition took place from 300 to $350^{\circ} \mathrm{C}$ with 137.80 $\mathrm{kJ} / \mathrm{mol}$. Xylan decomposition showed a peak between 250 and $300^{\circ} \mathrm{C}$ with an $202.74 \mathrm{~kJ} / \mathrm{mol}$. The decomposition of lignin took place over a broad temperature range from 200 to $700^{\circ} \mathrm{C}$ with an $151.55 \mathrm{~kJ} / \mathrm{mol}$. All the components showed an increase in endothermicity with reaction progression.

Figure 2. Comparison of (a) conversion and (b) conversion rates for cellulose, xylan, and lignin
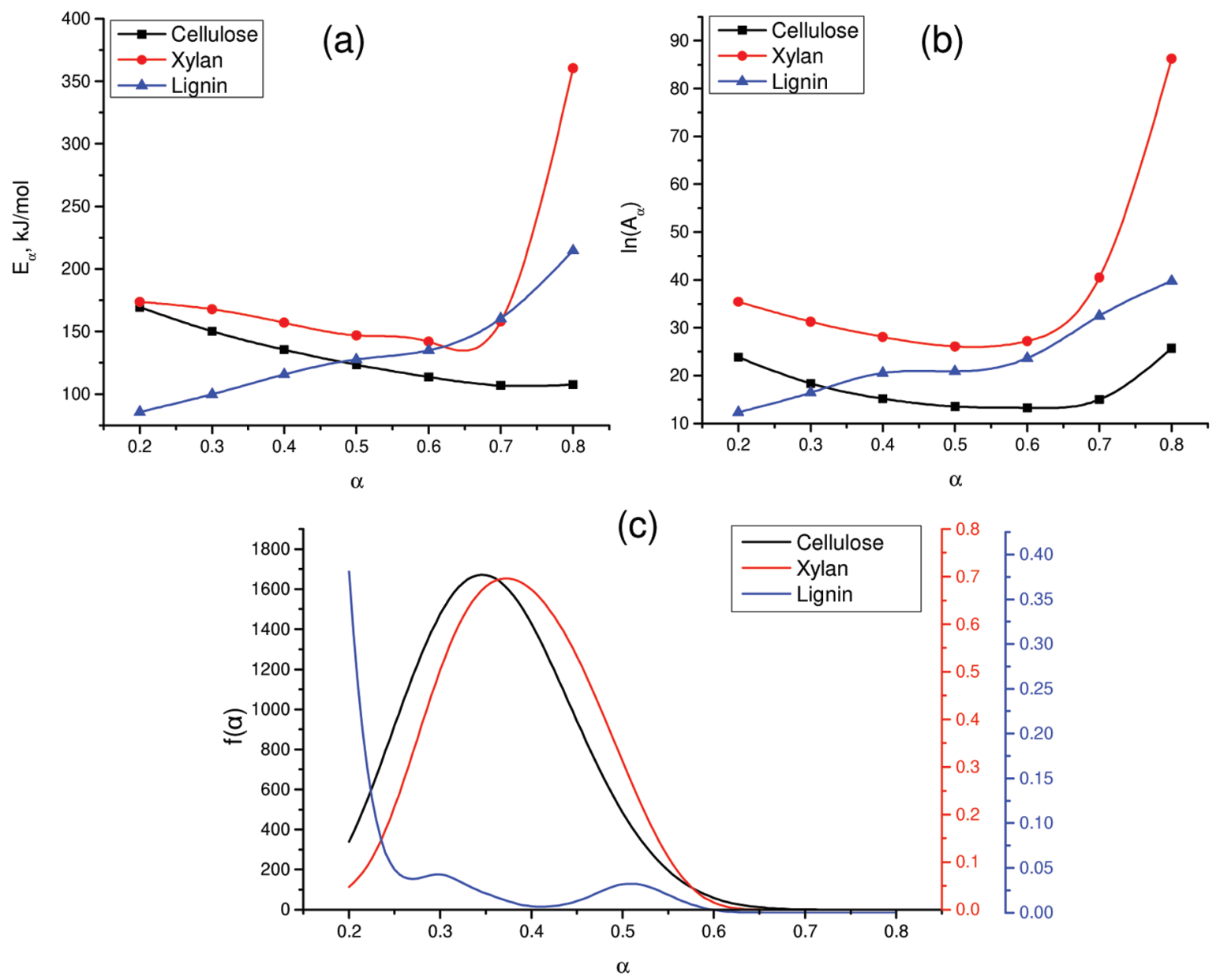

Figure 3. Kinetic analysis of decomposition of cellulose, xylan, and lignin: (a) $E_{\alpha}$ calculated from Friedman's method, (b) $T_{\alpha}$ calculated from Kissinger's equation, and (c) $f(\alpha)$ profile obtained by sustituting the values of and in TGA data 


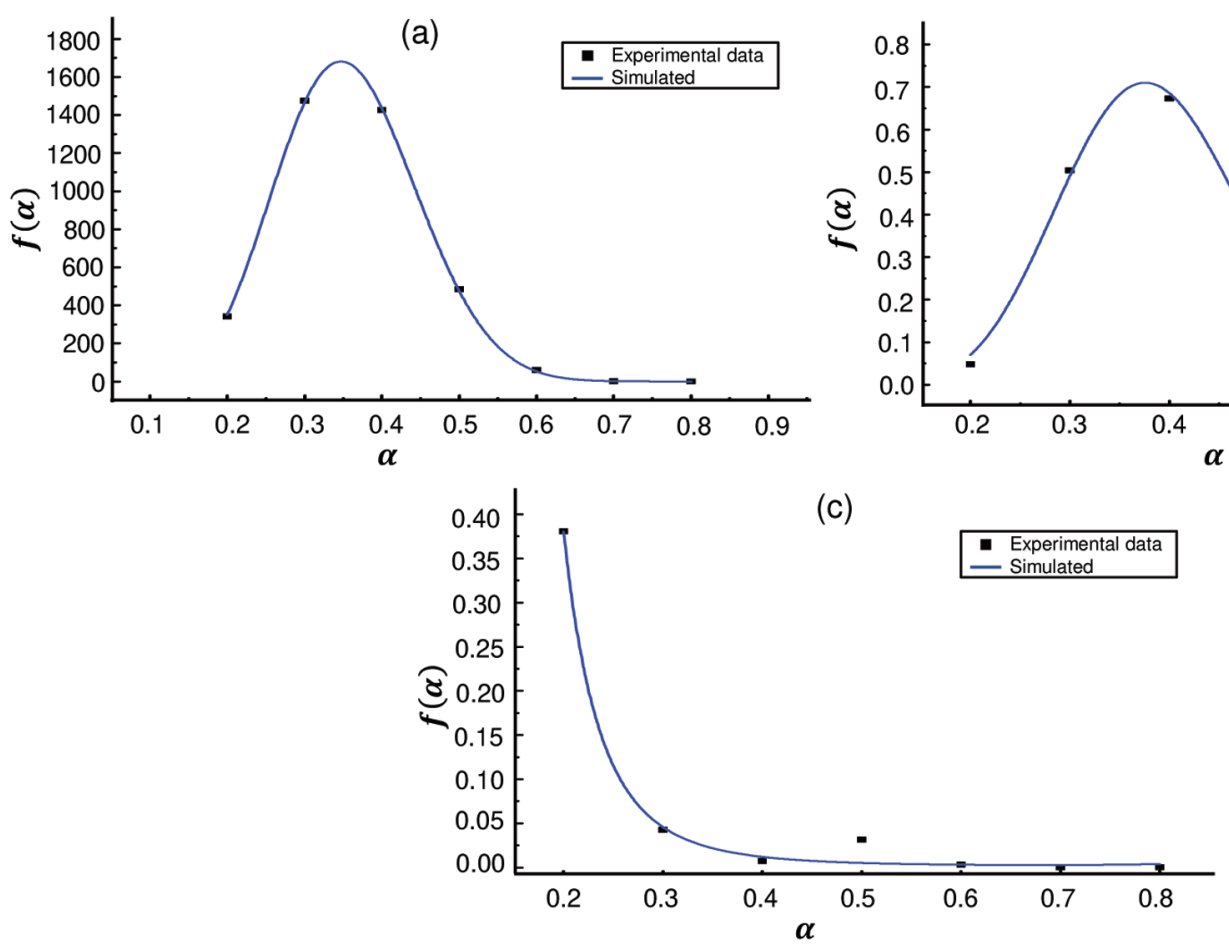

Figure 4. Experimental data and simulated profiles of $f(\alpha)$ for (a) cellulose, xylan, and lignin
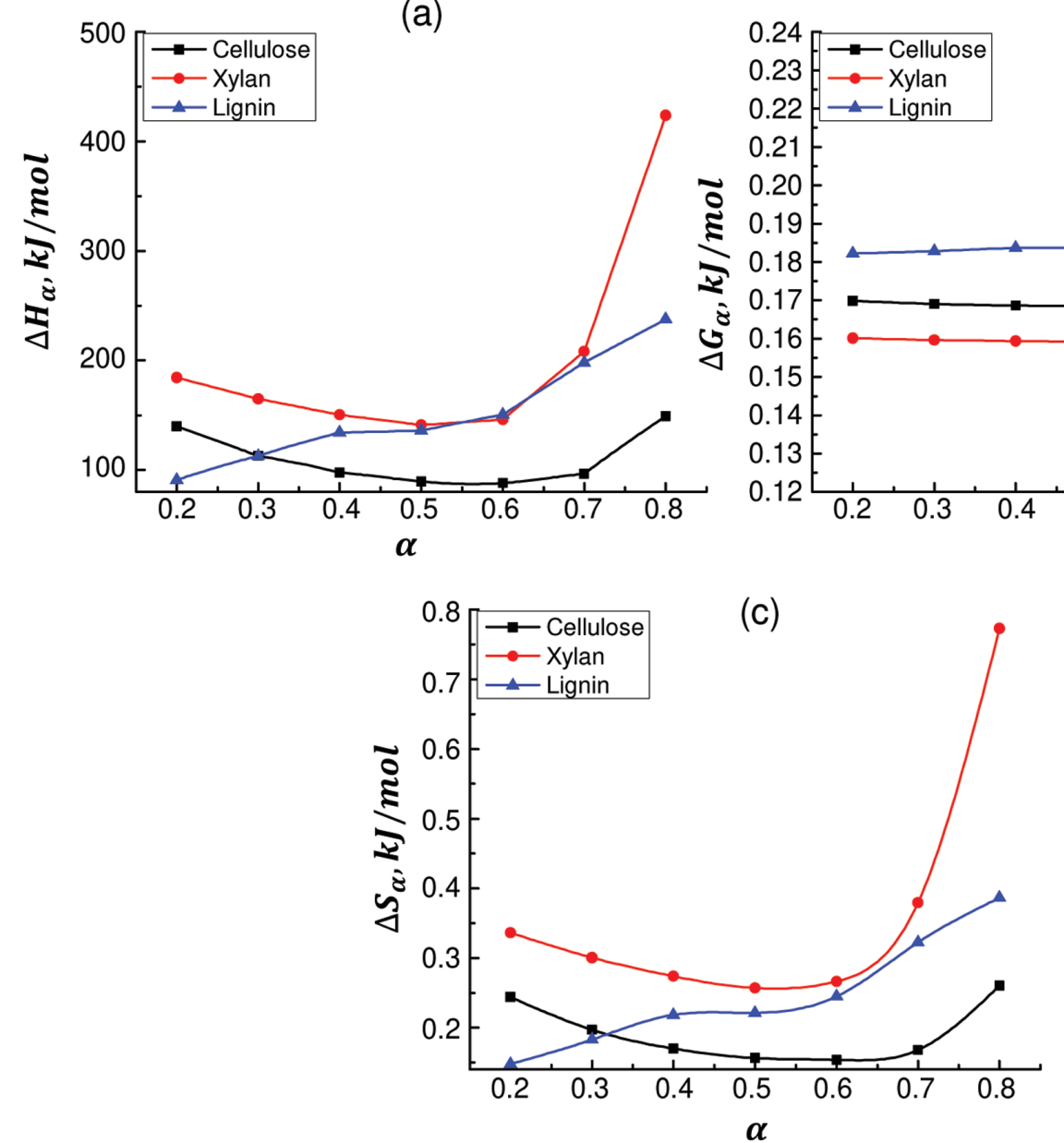

(c)

(b)

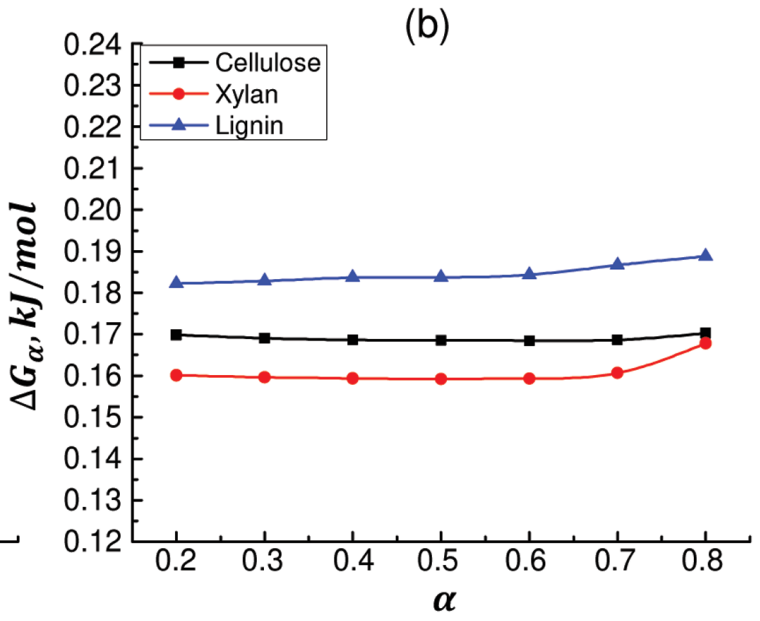




\section{Acknowledgments}

The authors would like to thank the Director, CSIR-Indian Institute of Petroleum (IIP) for support and encouragementand AcSIR for granting permission to conduct this research work at CSIR-IIP. The authors also thank Centre for High Technology (CHT) for providing financial assistance in the form of the GAP-3220 project.

\section{References}

Awasthi, A., Dhyani, V., Biswas, B., Kumar, J., Bhaskar, T., 2019. Production of phenolic compounds using waste coir pith: Estimation of kinetic and thermodynamic parameters. Bioresour. Technol. 274, 173-179. https://doi.org/https://doi.org/ 10.1016/j.biortech.2018.11.073

Dhyani, V., Awasthi, A., Kumar, J., Bhaskar, T., 2017. Pyrolysis of Sorghum straw: Effect of temperature and reaction environment on the product behavior. J. Energy Environ. Sustain. 4, 64-69.

Dhyani, V., Bhaskar, T., 2019. Chapter 9 - Pyrolysis of Biomass, in: Pandey, A., Larroche, C., Dussap, C.-G., Gnansounou, E., Khanal, S. K, Ricke, S. B.T-B.A.F. and C.P. for the P. of L. and G.B. (Second E. (Eds.), Biomass, Biofuels, Biochemicals. Academic Press, pp. 217-244. https://doi.org/https://doi.org/10.1016/B978-0-12-816856$1.00009-9$

Dhyani, V., Bhaskar, T., 2018a. A comprehensive review on the pyrolysis of lignocellulosic biomass. Renew. Energy 129, 695-716. https://doi.org/https:// doi.org/10.1016/j.renene.2017.04.035

Dhyani, V., Bhaskar, T., 2018b. Chapter 2 - Kinetic Analysis of Biomass Pyrolysis, in: Pandey, A. (Ed.), Waste Biorefinery: Potential and Perspectives. Elsevier, pp. 3983. https://doi.org/https://doi.org/10.1016/B978-0-444-63992-9.00002-1

Fekhar, B., Miskolczi, N., Bhaskar, T., Kumar, J., Dhyani, V., 2018. Co-pyrolysis of biomass and plastic wastes: investigation of apparent kinetic parameters and stability of pyrolysis oils, in: IOP Conference Series: Earth and Environmental Science. IOP Publishing, p. 12022.

Friedman, H.L., 1964. Kinetics of thermal degradation of char-forming plastics from thermogravimetry. Application to a phenolic plastic. J. Polym. Sci. Part C Polym. Symp. 6, 183-195. https://doi.org/10.1002/polc.507006012
Hergert, H.L., 1971. Lignins: Occurrence, formation, structure and reactions. by KV Sarkanen CH Ludwig, Wiley-Interscience 267.

Kaur, R., Gera, P., Jha, M.K., Bhaskar, T., 2018. Pyrolysis kinetics and thermodynamic parameters of castor (Ricinus communis) residue using thermogravimetric analysis Bioresour. Technol. 250, 422-428.

Kawamoto, H., 2017. Lignin pyrolysis reactions. J. Wood Sci. 1-16. https://doi.org/ 10.1007/s10086-016-1606-z

Kissinger, H.E., 1956. Variation of peak temperature with heating rate in differentia thermal analysis. J. Res. Natl. Bur. Stand. (1934). 57, 217. https://doi.org/10.6028/ jres.057.026

Miller, R.S., Bellan, J., 1997. A generalized biomass pyrolysis model based on superimposed cellulose, hemicelluloseand liqnin kinetics. Combust. Sci. Technol. 126, 97-137.

Patwardhan, P.R., Brown, R.C., Shanks, B.H., 2011. Understanding the fast pyrolysis of lignin. ChemSusChem 4, 1629-1636.

Šesták, J., Berggren, G., 1971. Study of the kinetics of the mechanism of solid-state reactions at increasing temperatures. Thermochim. Acta 3, 1-12. https://doi.org/10.1016/ 0040-6031(71)85051-7

Vyazovkin, S., Burnham, A.K., Criado, J.M., Pérez-Maqueda, L.A., Popescu, C. Sbirrazzuoli, N., 2011. ICTAC Kinetics Committee recommendations for performing kinetic computations on thermal analysis data. Thermochim. Acta 520,1-19. https:/ /doi.org/10.1016/j.tca.2011.03.034

Vyazovkin, S., Chrissafis, K., Di Lorenzo, M.L., Koga, N., Pijolat, M., Roduit, B. Sbirrazzuoli, N., Suñol, J.J., 2014. ICTAC Kinetics Committee recommendations for collecting experimental thermal analysis data for kinetic computations. Thermochim. Acta 590, 1-23. https://doi.org/10.1016/j.tca.2014.05.036

Wang, S., Dai, G., Yang, H., Luo, Z., 2017. Lignocellulosic biomass pyrolysis mechanism A state-of-the-art review. Prog. Energy Combust. Sci. 62, 33-86.

Yang, H., Yan, R., Chen, H., Lee, D.H., Zheng, C., 2007. Characteristics of hemicellulose, cellulose and lignin pyrolysis. Fuel 86, 1781-1788. https://doi.org/10.1016/ j.fuel.2006.12.013

Yeo, J.Y., Chin, B.L.F., Tan, J.K., Loh, Y.S., 2017. Comparative studies on the pyrolysis of cellulose, hemicellulose, and lignin based on combined kinetics. J. Energy Inst. 